\title{
DESEMPENHO TÉRMICO DE COBERTURA VEGETADA SOBRE GUARITA DE FIBRA DE VIDRO
}

\section{THERMAL PERFORMANCE OF A VEGETATED ROOF ON A FIBERGLASS SECURITY BOOTH}

\author{
Eduardo Krüger \\ Universidade Tecnológica Federal do Paraná, Curitiba, PR, Brasil, ekruger@utfpr.edu.br \\ Patricia Regina Chaves Drach ${ }^{2}$ \\ Universidade Estadual do Rio de Janeiro, Universidade Federal do Rio de Janeiro, Rio de Janeiro, RJ, Brasil, \\ patricia.drach@gmail.com \\ Cintia Akemi Tamura ${ }^{3}$ \\ Universidade Tecnológica Federal do Paraná, Curitiba, PR, Brasil, cintiatamura@gmail.com \\ Francine Kaviski ${ }^{4}$ \\ Universidade Tecnológica Federal do Paraná, Curitiba, PR, Brasil, f.kaviski@gmail.com
}

\begin{abstract}
Resumo
Neste trabalho é apresentada a avaliação do desempenho térmico de cobertura vegetada sobre guarita de fibra de vidro para primavera-verão de 2018 em Curitiba/PR. Compararam-se guaritas em condição experimental (ME) e controle (MC) para três configurações de cobertura (substrato; substrato e vegetação; substrato, vegetação e tela de sombreamento), com e sem sombreamento de janelas. A análise de conforto e estresse térmico seguiu parâmetros normativos de índice de bulbo úmido e temperatura de globo - IBUTG e temperatura efetiva - TE. A envoltória de fibra de vidro interferiu na temperatura do ar nos dois módulos, sendo a diferença na temperatura interna do $M C$ e $M E$ de apenas $2^{\circ} \mathrm{C}$. Entretanto, quanto às temperaturas de superfície sob a cobertura, o sistema de cobertura vegetada do ME ofereceu amortecimento e atraso térmico, atingindo uma diferença de até $12 \mathrm{~K}$ relativamente ao MC. Na comparação ME vs. MC, não se verificaram horas em estresse por calor no IBUTC, porém os valores de TE, em sua maioria, migraram para a condição de conforto, com a cobertura vegetada. Outra técnica explorada neste artigo é baseada na análise termográfica. Os resultados mostraram desempenho térmico superior do ME se comparado ao MC, confirmando as medições pontuais de temperatura de superfície.
\end{abstract}

Palavras-chave: Desempenho térmico. Cobertura verde. Guarita de fibra de vidro.

\begin{abstract}
The thermal performance of a vegetated roof in a fiberglass security booth was evaluated for spring-summer of 2018 in Curitiba/PR. An experimental (EM) and a control module (CM) of two equal security booths were compared for three roof configurations (substrate; substrate and vegetation; substrate, vegetation and shading mesh) and two window conditions (shaded and unshaded). Comfort and thermal stress analyses followed normative parameters of wet-bulb globe temperature (WBGT) and effective temperature (ET). The fiberglass envelope interfered with the air temperature in both units. The indoor temperature in MC and ME differed by $2{ }^{\circ} \mathrm{C}$. However, the vegetated cover system of the $M E$ offered fluctuations reduction and thermal delay, reaching a peak difference of $12 \mathrm{~K}$ when compared to MC. Hours in thermal stress were not identified in CM and EM for WBGT, though with the vegetated cover hours in thermal comfort were generally enhanced in terms of ET. Another technique explored in this article consisted of a thermographic analysis. Results showed higher thermal performance of EM relative to CM, confirming the spot surface temperature measurements.
\end{abstract}

Keywords: Thermal performance. Green cover. Fiberglass security booth.

How to cite this article:

KRÜGER, E.; DRACH, P. R. C.; TAMURA, C. A.; KAVISKI, F. Desempenho térmico de cobertura vegetada sobre guarita de fibra de vidro. PARC Pesquisa em Arquitetura e Construção, v. 10, p. e019026, 28 jul. 2019. DOI: https://doi.org/10.20396/parc.v10i0.8654277 


\section{Introdução}

Áreas vegetadas no espaço urbano melhoram a qualidade espacial por meio de mecanismos como a absorção de dióxido de carbono, a produção de oxigênio e a filtragem do ar. Segundo Yeang (2006) uma única árvore pode capturar $160 \mathrm{~kg}$ de carbono/ano, o que corresponde a uma taxa de absorção de $1,63 \mathrm{~kg} / \mathrm{m}^{2}$.

Ademais, a presença de áreas permeáveis arborizadas nas cidades contribui para a amenização do efeito de ilhas de calor. A presença de áreas permeáveis arborizadas pode promover a ocorrência de temperaturas entre $6{ }^{\circ} \mathrm{C}$ a $8{ }^{\circ} \mathrm{C}$ inferiores às áreas construídas, devido à ação de mecanismos como evapotranspiração e sombreamento local (NIACHOU et al., 2001; CORBELLA; YANNAS, 2003).

Em edificações, a utilização das chamadas tecnologias verdes pode ser eficaz na minimização dos efeitos da insolação em coberturas, proporcionando conforto térmico aos usuários. A configuração desses sistemas usualmente utiliza diferentes técnicas sustentáveis, entre elas a coleta de água pluvial, a utilização de materiais biodegradáveis, painéis solares, telhados frios (cool roof), tetos reservatórios (blue roof) e cobertura com vegetação (green roof).

Em coberturas vegetadas, em razão das propriedades térmicas do substrato, os efeitos de fluxos de calor que geram aquecimento a partir de ganhos solares na cobertura são proporcionais aos índices de condutividade térmica e de difusividade térmica, respectivamente (VERA et al., 2017). Além disso, o comportamento do fluxo de calor é retardado em função das resultantes de sombreamento, de isolamento, de evapotranspiração e da massa térmica dos materiais que compõem a cobertura (TABARES-VELASCO; SREBRIC, 2012).

Um sistema padrão de cobertura vegetada é constituído por diferentes materiais, que são definidos de acordo com sua durabilidade, necessidade de manutenção e valor econômico (SAVI, 2012). Estes conjuntos de materiais são dispostos em camadas na seguinte sequência: 1 - Camada vegetal, 2 - Camada de substrato, 3 - Camada antienraizamento, 4 - Camada drenante, 5 - Camada impermeabilizante e 6 - Estrutura da cobertura (MINKE, 2004; LOPES, 2007; FERRAZ, 2012; SAVI, 2015), conforme ilustra a Figura 1.

Figura 1 - Componentes de uma cobertura vegetada

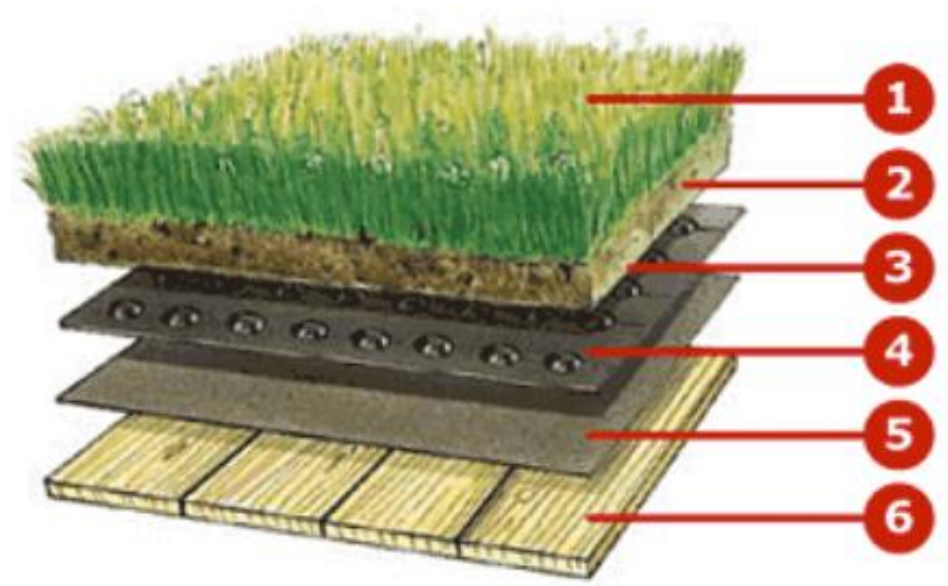

Fonte: Triton systems (2011).

A camada vegetal (1) é formada por espécies vegetais, que fixam o carbono e cedem oxigênio à atmosfera. A seguir, encontra-se a camada de substrato (2), um composto à 
base de solo orgânico, que tem a finalidade de dar sustentação e suporte nutritivo para a camada de vegetação. Logo abaixo, localiza-se a camada anti-enraizamento (3), que possui função filtrante, ou seja, impede a passagem de fragmentos do substrato e do vegetal para a faixa de drenagem do sistema. Subsequentemente a esta membrana, é aplicada a camada drenante (4) que transfere o excesso da água para o exterior do sistema e geralmente é constituída por mantas geocompostas extrudadas - pequenos copos vazados. Em alguns sistemas, a camada drenante pode armazenar água para as plantas em período de estiagem. A camada impermeabilizante (5), por sua vez, consiste em uma película que impede o contato direto de fluidos e da umidade junto à superfície da cobertura. Por fim, a estrutura da cobertura da edificação (6) é a base de apoio do sistema e pode ser uma laje, telhas ou sustentação específica fabricada em alvenaria ou madeira.

Para garantir a eficácia do sistema, a escolha de uma camada está intimamente ligada à outra. Sendo assim, as três principais variáveis que devem ser analisadas previamente à execução da cobertura vegetada para a definição do sistema são o peso, o custo e a manutenção do sistema de cobertura selecionado (VIJAYARAGHAVAN, 2016).

Quanto à sua tipologia, a International Green Roof Association - IGRA (IGRA, 2017) classifica as coberturas vegetadas em extensivas, semi-intensivas e intensivas. Tal classificação é definida pelo peso e manutenção em razão da utilização, pelas espécies vegetais utilizadas e pela espessura do substrato.

A cobertura vegetada do tipo extensivo é um sistema leve e requer manutenção reduzida ou até mesmo nenhuma manutenção. Tem como objetivo o auxílio à drenagem de águas pluviais e a atenuação dos efeitos da radiação solar incidente na edificação (FERRAZ, 2012). Não permite pisoteio e as espécies a serem utilizadas são limitadas às rústicas e rasteiras, de pouco desenvolvimento radicular, que se adequem a uma camada de substrato de 0,07 a 0,20 m.

O segundo tipo de cobertura, o semi-intensivo, é uma camada intermediária que permite o plantio de espécies de médio porte, como arbustos. Exige manutenção periódica, como podas regulares, possuindo uma camada de substrato entre 0,12 a 0,25 m (RAJI; TENPIERIK; VAN DEN DOBBELSTEEN, 2015).

O terceiro tipo de cobertura, o intensivo, é semelhante a um jardim. Possui o mesmo desempenho dos demais sistemas apresentados, tendo como diferencial a possibilidade de receber espécies de grande porte, tais como árvores. Este sistema pode ser instalado somente em superfícies planas, a fim de evitar movimentos do solo (RAJI; TENPIERIK; VAN DEN DOBBELSTEEN, 2015). A espessura do substrato para essa tipologia é maior, sendo no mínimo de $0,40 \mathrm{~m}$, podendo ir até $1,20 \mathrm{~m}$. Por isso, permite pisoteio e a apropriação por pedestres, como no caso de áreas públicas (FERRAZ, 2012). O Quadro 1 sintetiza as informações acerca dos tipos de coberturas verdes.

O tema central deste trabalho baseia-se na análise de desempenho térmico de coberturas vegetadas quando aplicadas a guaritas de fibra de vidro comumente adotadas em condomínios e portarias de áreas fechadas. Uma vez que tais guaritas consistem em ambientes de trabalho, o foco está na garantia de condições de conforto e proteção, reduzindo-se o nível de estresse térmico interno. Considerando uma aplicação em guaritas leves, definiu-se o peso do protótipo de cobertura vegetada para os experimentos como principal critério para sua confecção, optando-se pela utilização de cobertura vegetada do tipo extensivo. 
KRÜGER, Eduardo et al.

Desempenho térmico de cobertura vegetada sobre guarita de fibra de vidro

\begin{tabular}{|c|c|c|c|}
\hline \multirow{2}{*}{ Características } & \multicolumn{3}{|c|}{ Tipos de Cobertura vegetada } \\
\hline & Extensivo & Semi-intensivo & Intensivo \\
\hline Fertilização & Baixo & Periodicamente & Alto \\
\hline Irrigação & Não & Periodicamente & Regularmente \\
\hline Vegetação & $\begin{array}{c}\text { Musgos, suculentas, } \\
\text { folhagens e gramíneas }\end{array}$ & $\begin{array}{c}\text { Gramíneas, folhagens } \\
\text { e arbustos }\end{array}$ & $\begin{array}{l}\text { Forrações, folhagens, } \\
\text { arbustos e árvores }\end{array}$ \\
\hline Espessura & $<0,07 m-0,20 m>$ & $<0,12 m-0,25 m>$ & $<0,40 m-1,20 m>$ \\
\hline Peso & $60-150 \mathrm{~kg} / \mathrm{m}^{2}$ & $120-200 \mathrm{~kg} / \mathrm{m}^{2}$ & $180-500 \mathrm{~kg} / \mathrm{m}^{2}$ \\
\hline Custo médio & Baixo & Médio & Alto \\
\hline Uso & Proteção & Terraço jardim - efeito visual & Terraço jardim - para ocupação \\
\hline $\begin{array}{l}\text { Capacidade de } \\
\text { carga }\end{array}$ & $\begin{array}{l}\text { Suporta pouca carga, camada } \\
\text { reduzida de } \\
\text { Substrato limitando o uso } \\
\text { de espécies. }\end{array}$ & $\begin{array}{l}\text { Não suporta pisoteio. } \\
\text { Camada intermediária com } \\
\text { a espessura do substrato maior a } \\
\text { fim de permitir espécies } \\
\text { de médio porte. }\end{array}$ & $\begin{array}{l}\text { Suporta pisoteio e cargas } \\
\text { adicionais como mobiliários } \\
\text { urbanos. Exige camada } \\
\text { maior de substrato. Exige } \\
\text { maior atenção e cuidado. }\end{array}$ \\
\hline
\end{tabular}

Fonte: Adaptado de IGRA (2007).

\section{Método}

As guaritas testadas são fabricadas a partir do compósito plástico reforçado em fibra de vidro (PRFV), o mesmo utilizado em outros produtos tais como caixas d'água e piscinas, compostas por matrizes poliméricas do tipo termoplástico. Este material é usualmente empregado na construção civil devido à sua leveza, desempenho mecânico, resistência à corrosão, custo reduzido no ciclo de vida, além de baixa degradabilidade do material (TECH COMPOSITES, 2018). Ademais, apresentam resistência mecânica comparável a materiais como madeira e metal. Sobre este tipo de guarita, foi aplicado um sistema de cobertura vegetada.

\section{Localização do estudo e implantação dos módulos}

A implantação dos módulos experimentais ocorreu no canteiro experimental da Universidade Tecnológica Federal do Paraná (UTFPR), a oeste da região central da cidade (Figura 2).

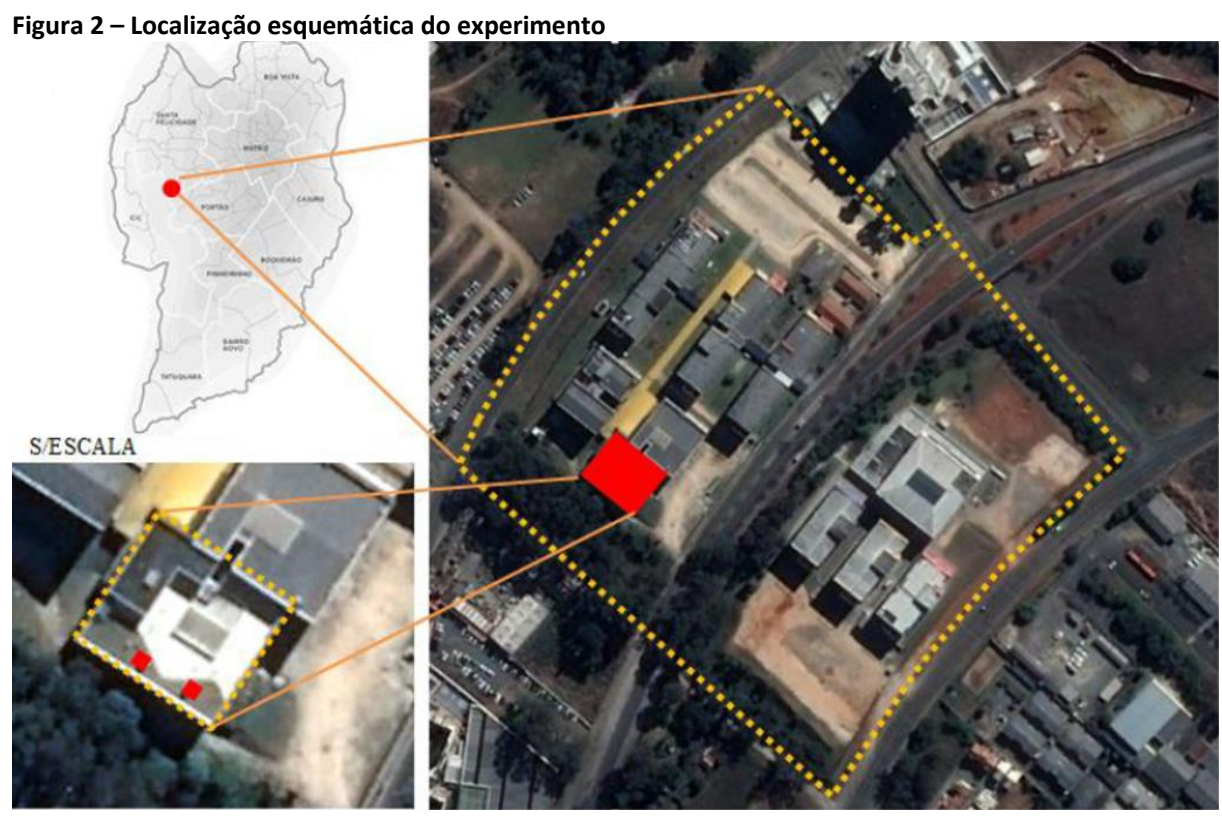

Fonte: Os autores.

A implantação das guaritas foi definida após realização de estudo solar das fachadas em função da latitude local. Este procedimento deu-se com o auxílio do software 
SketchUp ${ }^{\circledR}$, com o objetivo de proporcionar condições locais semelhantes para as duas guaritas de pesquisa com o maior aproveitamento de horas com sol incidente nas fachadas, porém com o menor sombreamento mútuo. Considerou-se o comportamento solar durante os solstícios e equinócios em três horários (8hoo, 12hoo e 17hoo). A partir dos resultados obtidos, optou-se pela implantação das guaritas conforme a Figura 3 .

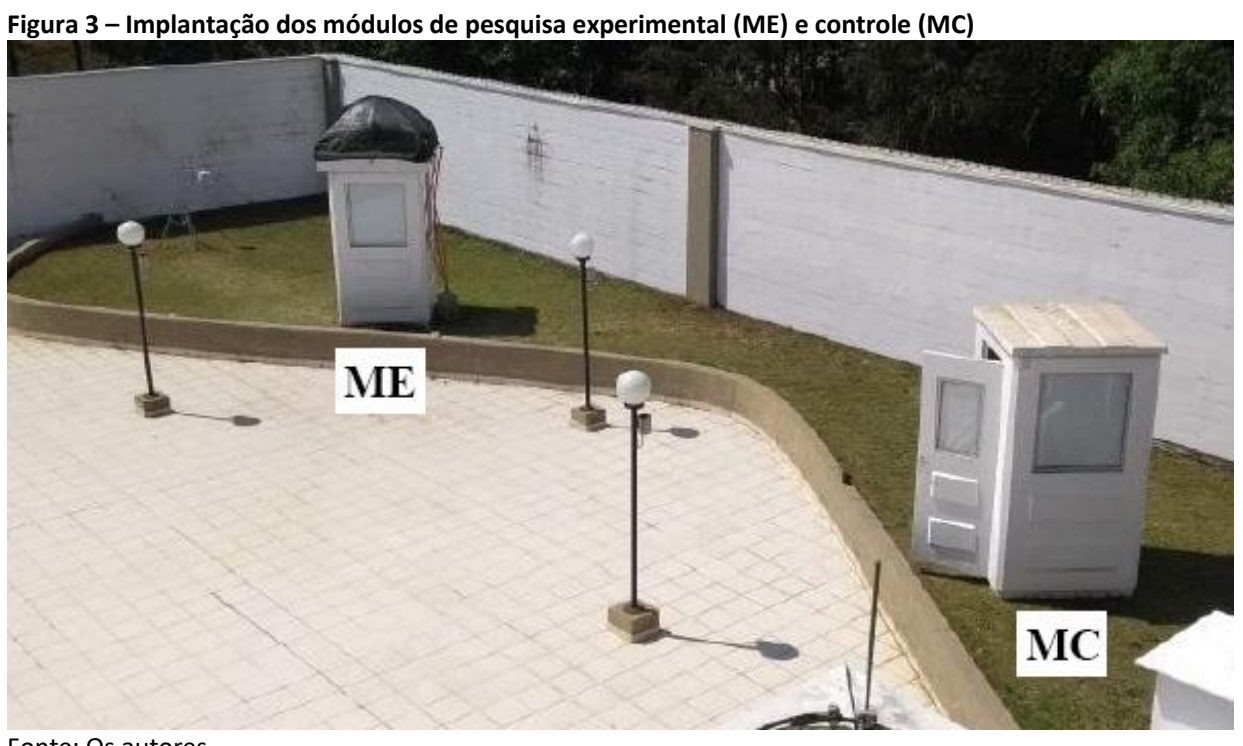

Fonte: Os autores.

\section{Guaritas analisadas}

O presente estudo utilizou duas guaritas compostas de fibra de vidro, denominadas módulo controle (MC), sem quaisquer modificações e conforme é comercializada; e módulo experimental (ME). Os dois módulos estavam desocupados e, portanto, não havia carga interna proveniente de iluminação artificial ou de equipamentos elétricos (computador, telefone etc.) bem como da presença humana. Suas principais dimensões e tipologias de aberturas são apresentadas na Figura 4.

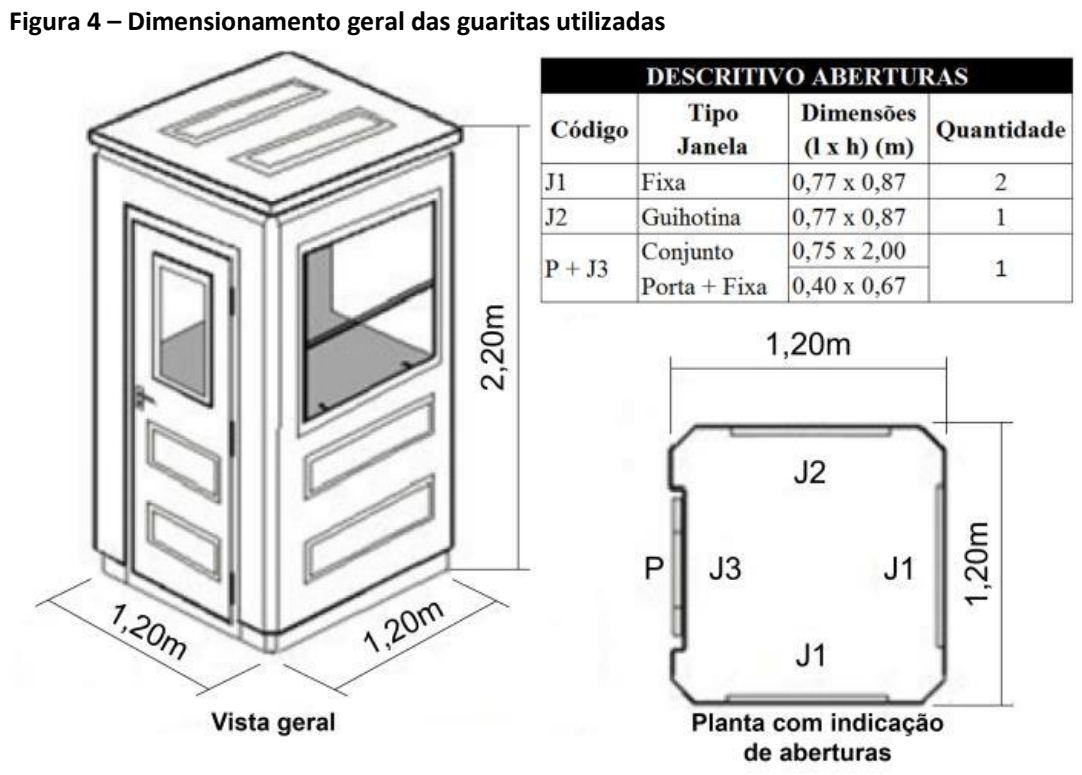

Fonte: Adaptado de FBL (2017).

As guaritas, feitas em polímero reforçado com fibra de vidro (PRFV) e acabamento gelcoat (resina pintada) possuem espessura de parede de $3 \mathrm{~mm}$, com dimensões básicas 
de $1,20 \mathrm{~m} \times 1,20 \mathrm{~m} \times 2,20 \mathrm{~m}$. As aberturas são compostas por vidro temperado translúcido com espessura de $3 \mathrm{~mm}$. O modelo utilizado não possui mecanismos de controle térmico ou acústico (FBL, 2017). Para análise de desempenho térmico, avaliaram-se duas condições de exposição: aberturas com e sem sombreamento, de forma a verificar a interferência das incidências solares diretas. Para o fechamento das aberturas, recorreu-se ao uso da manta reflexiva tipo foil dupla face, com uma face metalizada e outra na cor branca (voltada para o exterior).

O módulo MC permaneceu com a forma padrão fornecida pelo fabricante, enquanto que o módulo ME recebeu o protótipo de cobertura vegetada.

\section{Sistema cobertura vegetada aplicado ao ME}

O ME recebeu sobre a cobertura um sistema de cobertura vegetada construído a partir das dimensões básicas da guarita simples em compensado naval, com $20 \mathrm{~mm}$ de espessura e dimensões externas de 1,35 $\mathrm{m} \times 1,35 \mathrm{~m} \times 0,25 \mathrm{~m}$. O sistema representou uma sobrecarga de $220 \mathrm{~kg}$ sobre a cobertura da guarita, o que corresponde à carga de uma cobertura vegetada do tipo extensiva (cf. Quadro 1). Como a capacidade de sobrecarga da guarita usada equivale a aproximadamente $200 \mathrm{~kg}$, por precaução, o ME recebeu reforço estrutural composto por ripas de cedrinho $(3 \times 5 \mathrm{~cm})$, sendo que durante todo o período de realização da pesquisa não foram identificados sinais de comprometimento da estrutura da guarita.

\section{Corpo do protótipo}

Inicialmente, as peças de compensado naval receberam individualmente duas demãos de stain, um tipo de Verniz que penetra nas fibras da madeira e protege o material exposto às intempéries e fungos. Após a montagem por colagem e parafusamento, o protótipo recebeu mais uma mão de stain. $O$ acabamento externo da caixa foi feito com três demãos de tinta a óleo, base acetinada, na cor branca. Após a secagem, executouse a impermeabilização do protótipo com uma dupla camada de manta asfáltica, reforçada com véu de poliéster entre uma mão e outra, como recomendado para instalação de coberturas vegetadas em contêineres. Como acabamento, nas bordas do protótipo, utilizou-se manta de foil dupla face como rufo, impedindo o contato direto da vegetação e do substrato com a madeira, de forma a proteger e aumentar a vida útil do sistema. Finalizada a estrutura do sistema, prepararam-se as camadas da cobertura vegetada, conforme demonstrado da Figura 5.

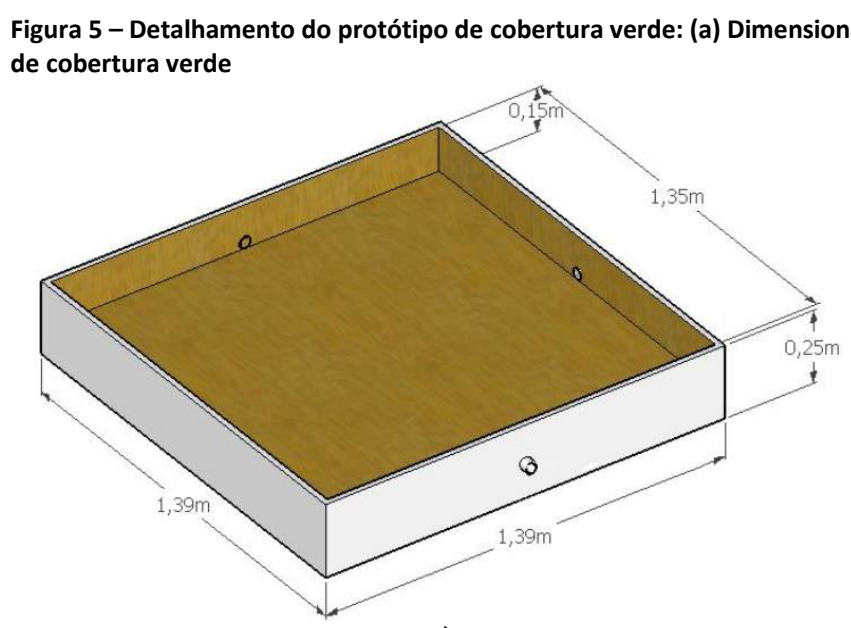

Fonte: Os autores.

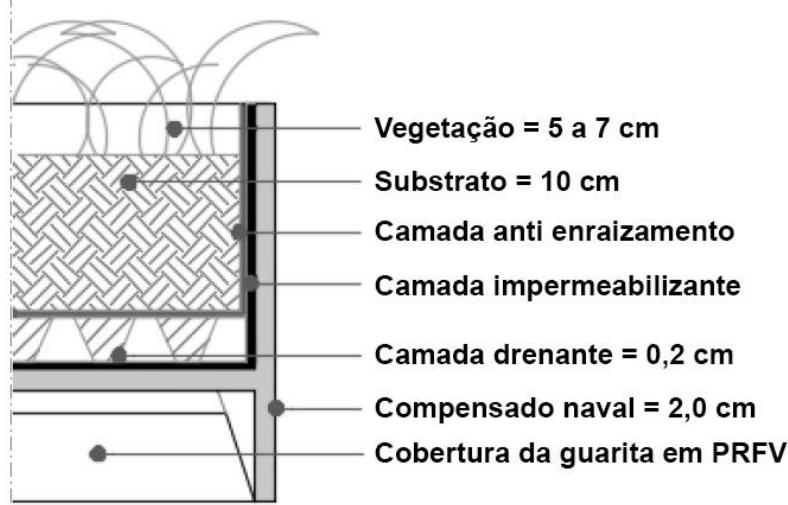

b) 


\section{Substrato}

Para a definição da composição do substrato, assumiram-se os valores de referência descritos por Miller (2014), que avaliou a interferência da composição de coberturas vegetadas para Curitiba. Adotou-se a seguinte composição: terra (35\%), turfa (20\%), casca de arroz carbonizada (40\%) e vermiculita (5\%), que possibilita melhor desenvolvimento da vegetação, bem como retenção das águas pluviais (MILLER, 2014).

Vegetação

A partir de um levantamento de espécies mais adaptadas às condições climáticas locais, optou-se por duas espécies: a dinheiro-em-penca (Callisia repens), uma herbácea nativa, perene e rasteira (GUERRA JÚNIOR, 2013) e de rápido enraizamento atingindo 5 a $25 \mathrm{~cm}$ de altura (NOYA et al., 2017); e a dianela (Dianella caerulea), uma herbácea perene que alcança 0,8 a 5,0 cm de altura (RAZZAGHMANESH; BEECHAM; KAZEMI, 2014). Um mês após a colocação do substrato, realizou-se o plantio das mudas das duas espécies vegetais. Estas foram irrigadas manualmente durante os cinco primeiros dias após o plantio, e após este período, uma vez por semana, durante três semanas. Após este período, não houve necessidade de regas nem manutenção do sistema, seja para limpeza ou podas.

Tela de sombreamento

Após o monitoramento das primeiras configurações testadas, acrescentou-se ao sistema uma tela de sombreamento de polietileno, com a finalidade de avaliar sua possível interferência térmica. Optou-se por tela com 50\% de proteção solar. Para sua instalação, preparou-se uma estrutura em forma de cúpula feita com barras de ferro de $3 / 4 "$. Sobre esta, foi acomodada a tela de sombreamento (Figura 6).

Figura 6 - Implantação de tela de sombreamento sobre a cobertura vegetada: (a esquerda) Estrutura em ferro e (a direita) Estrutura com tela de sombreamento

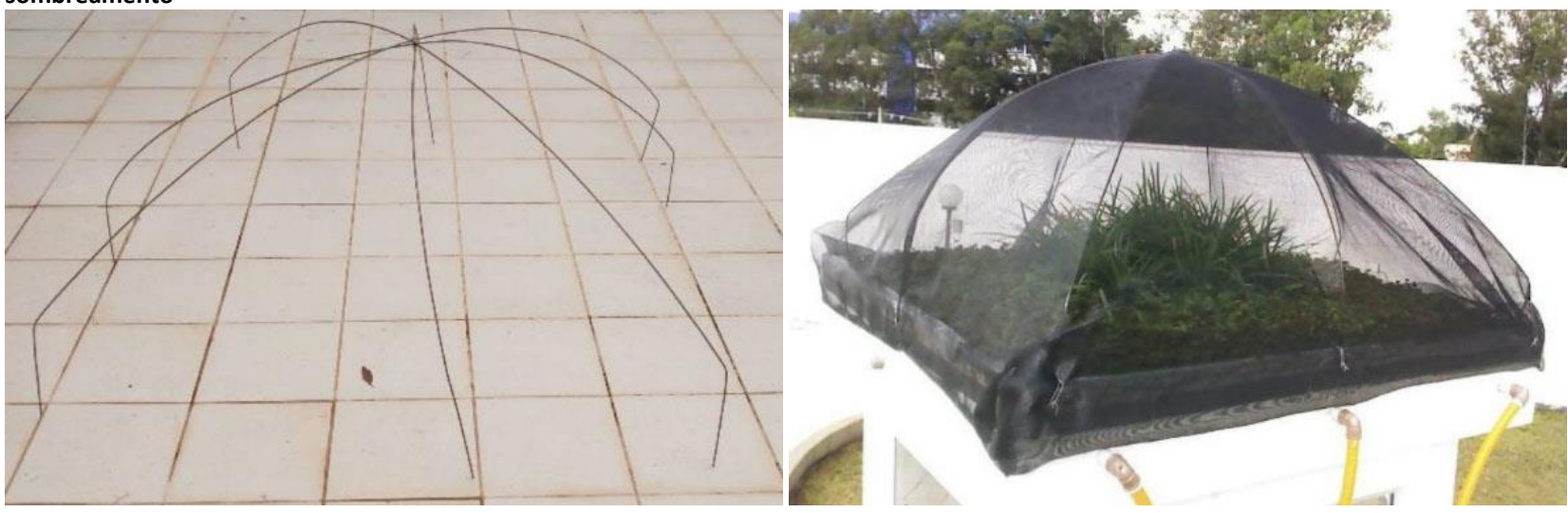

Fonte: Os autores.

\section{Clima local}

O município de Curitiba está localizado na região sul do Brasil, latitude $25^{\circ} 25^{\prime} 40^{\prime \prime} \mathrm{S}$ e altitude de 934 m (IPARDES, 2018). O clima é mesotérmico e temperado oceânico úmido - Cfb de acordo com a classificação Köppen-Geiger (PEEL; FINLAYSON; MCMAHON, 2007), com verões e invernos bem definidos. As massas de ar atuante nessa região são a tropical atlântica (quente) e polar atlântica (frio). Segundo dados da rede do Instituto Nacional De Meteorologia (INMET) entre 1981 a 2010, a temperatura média compensada registrada foi de $17,4^{\circ} \mathrm{C}$, sendo julho o mês de mais frio com média de $13,5^{\circ} \mathrm{C}$ e fevereiro o mais quente com a temperatura média anual de $21^{\circ} \mathrm{C}$. Quanto ao nível de precipitação acumulada nesse mesmo período, os índices pluviométricos anuais chegam a 1.575,8 
$\mathrm{mm}$, sendo que agosto apresenta menor índice de chuvas com média de 74,0 mm e janeiro é o mês com maior volume de precipitações, com média acumulada de 218,3 mm (INMET, 2018).

Com relação ao Zoneamento Bioclimático, Curitiba enquadra-se na Zona Bioclimática 1ZB1. No Quadro 2, são apresentadas diretrizes construtivas para o desempenho térmico de habitações unifamiliares de interesse social, de acordo com a NBR-15220 (2005). Uma vez que esta norma foi criada a partir de recomendações de adequação climática, verifica-se que o condicionamento térmico passivo mediante cobertura vegetada é uma técnica favorável às práticas construtivas recomendadas para a região, quando reconhecida como estratégia de alta inércia térmica associada ao aquecimento solar.

Quadro 2 - Diretrizes construtivas para Zona Bioclimática 1

\begin{tabular}{|c|c|c|c|c|c|}
\hline \multirow[t]{2}{*}{ ZB } & \multicolumn{2}{|c|}{$\begin{array}{l}\text { Aberturas: (1) para ventilação e (2) } \\
\text { para sombreamento }\end{array}$} & \multicolumn{2}{|c|}{$\begin{array}{l}\text { Vedações externas: (3) parede } \\
\text { e (4) cobertura }\end{array}$} & \multirow{2}{*}{$\begin{array}{l}\text { Condicionamento } \\
\text { térmico passivo }\end{array}$} \\
\hline & (1) & (2) & (3) & (4) & \\
\hline ZB -1 Curitiba - PR & Médias & $\begin{array}{l}\text { Permitir sol durante } \\
\text { o período frio }\end{array}$ & Leve & Leve isolada & $\begin{array}{c}\text { Aquecimento solar da edificação } \\
\text { e vedações internas pesadas } \\
\text { (inércia térmica) }\end{array}$ \\
\hline
\end{tabular}

Fonte: Adaptado da NBR 15220-3 (ABNT, 2005)

A introdução da vegetação sobre a superfície da cobertura permite a interceptação dos raios solares e o bloqueio da ação dos ventos, responsável pela perda térmica do substrato (MINKE, 2004). Ao estabilizar a temperatura ao longo do dia, tendo em vista que o sistema de cobertura acrescenta grande massa térmica ao ambiente, garante-se menor amplitude térmica diária (KRÜGER; BARBOSA, 2008).

\section{Monitoramento térmico}

A análise do desempenho térmico das guaritas ( $M C$ e $M E$ ) foi feita por meio da observação e da comparação de dados coletados no período de primavera de 2017 e verão 2018. A escolha desse período se deu para evitar ao máximo a ocorrência de precipitações, mais intensificadas a partir do final do ano, embora já com presença de situações de calor. Avaliaram-se variáveis como temperatura do ar, temperaturas de superfície e umidade do ar. A análise de conforto térmico foi realizada a partir de parâmetros normativos, pela NR-24 (BRASIL, 1993) e pela NR-17 (BRASIL, 2015).

Períodos de monitoramento e configurações analisadas

Os períodos de monitoramento para a análise de desempenho térmico da cobertura vegetada compreenderam os meses de outubro de 2017 a janeiro de 2018. De forma a viabilizar comparativos entre as cinco configurações avaliadas, calculou-se o coeficiente do dia padrão (DP, em Kelvin, segundo FERNANDES; KRÜGER; ROSSI, 2017) (Equação 1), o qual representa a maior oscilação térmica para o semiciclo mais longo ocorrido no espaço de 24 horas.

$$
D P=T_{m a ́ x} d 1-T_{m i ́ n} d 2
$$

Na qual:

$$
\begin{aligned}
& \mathrm{T}_{\text {máx }} \mathrm{d} 1 \text { = temperatura máxima do dia verificado }\left({ }^{\circ} \mathrm{C}\right) ; \\
& \mathrm{T}_{\text {mín }} \mathrm{d} 2 \text { = temperatura mínima do dia seguinte ao verificado }\left({ }^{\circ} \mathrm{C}\right) .
\end{aligned}
$$

A Tabela 1 apresenta as configurações testadas, os períodos avaliados e os dias padrão encontrados para cada situação. As iniciais utilizadas (Cód.) referem-se à descrição apresentada na sequência. 
KRÜGER, Eduardo et al.

Desempenho térmico de cobertura vegetada sobre guarita de fibra de vidro

\begin{tabular}{|c|c|c|c|c|c|c|c|c|}
\hline \multicolumn{4}{|c|}{ Configurações } & \multicolumn{3}{|c|}{ Período de monitoramento } & \multicolumn{2}{|c|}{ Dia Padrão } \\
\hline № & Cód. & $\begin{array}{c}\text { Elementos da } \\
\text { cobertura vegetada }\end{array}$ & Janela & $\mathrm{n}$ & Início & Fim & Data & $\mathrm{DP}(\mathrm{K})$ \\
\hline 1 & SF & Substrato & Sombreada & 12 & 3-nov & 15-nov & 12-nov & 17,5 \\
\hline 2 & SVF & Substrato + vegetação & Sombreada & 10 & 30-nov & 10-dez & 8-dez & 13,7 \\
\hline 3 & SVA & Substrato + vegetação & Sem proteção solar & 6 & 21-dez & 27-dez & 22-dez & 10,9 \\
\hline 4 & SVTA & Substrato + vegetação + tela & Sem proteção solar & 7 & 29-dez & 5-jan & 4-dez & 16,2 \\
\hline 5 & SVTF & Substrato + vegetação + tela & Sombreada & 7 & 7-jan & 14-jan & 13-jan & 7,9 \\
\hline 6 & SVF Extra & Substrato + vegetação & Sombreada & 11 & 31-mai & 10-jun & 31-mai & 11,6 \\
\hline
\end{tabular}

Legenda: SF = Cobertura apenas com substrato e com janela sombreada; SVF = Cobertura apenas com substrato e vegetação e com janela sombreada; SVA = Cobertura apenas com substrato e vegetação com janela não-sombreada; SVTA = Cobertura apenas com substrato e vegetação com janela nãosombreada, com tela de sombreamento sobre a vegetação; SVTF = Cobertura apenas com substrato e vegetação com janela sombreada, com tela de sombreamento sobre a vegetação; SVF Extra = condição SF, após um ano de implantação. Fonte: Os autores.

A partir da Tabela 1, pode ser observado que as configurações tiveram como base o substrato, inicialmente sem vegetação - linha número 1. Foram testadas situações para avaliar as variações resultantes de ganhos solares internos, ou seja, com as janelas protegidas e sem proteção contra ganhos solares. Foi também testada a contribuição de uma tela de sombreamento para a redução da carga térmica na cobertura (configurações 4 e 5). Complementarmente, foram tomadas duas semanas em junho de 2018 para investigar a fundo o efeito da estratificação vertical da temperatura do ar com e sem a cobertura vegetada (ME versus MC, "SVF Extra"), uma vez que as medições anteriores de perfil vertical ocorreram apenas em ME. Observa-se que ambos os períodos analisados excluem o período de estabilização térmica do ar no interior das guaritas após a instalação dos equipamentos de monitoramento, que foi de 24 horas.

Medições de temperatura e umidade

Realizou-se o monitoramento das variáveis de temperatura e umidade com data loggers portáteis de diferentes fabricantes e modelos, os quais foram aferidos previamente antes do início dos registros, com correção dos valores registrados a partir da média dos registros. Para temperatura de globo $\left(\mathrm{T}_{\mathrm{g}}\right)$, foram utilizados equipamentos HOBO U10001 no interior de globos de PVC com $15 \mathrm{~cm}$ de diâmetro; e TAGTEMP STICK, com precisão semelhante $\left(\sim 0,5^{\circ} \mathrm{C}\right)$; para a temperatura de superfície $\left(\mathrm{T}_{\mathrm{s}}\right)$, empregaram-se TAGTEMP NFC com cabo do tipo sonda, os quais foram recobertos com EPS para evitar efeitos de trocas térmicas por convecção; e, por fim, para o par de medidas temperatura $\left(\mathrm{T}_{\mathrm{a}}\right.$ ) e umidade do ar (UR), utilizaram-se LOGBOX-RHT, conforme a disposição nos módulos apresentada na Figura 7.

A disposição destes sensores no interior das guaritas obedeceu às recomendações definidas pela norma ISO 7726:1998, que regulamenta métodos e instrumentos para medições térmicas (ISO, 1998). Para garantir o correto posicionamento dos sensores de temperatura ambiente, a 0,10 m, 1,10 m e 1,70 m da base construiu-se um suporte de madeira semelhante a um pedestal contendo marcações e encaixes para fixação dos mesmos. Para o cálculo do índice de bulbo úmido e temperatura de globo (IBUTG), considerou-se que o trabalho no ambiente é predominantemente realizado em pé, sendo a referência de 1,10 $\mathrm{m}$ adotada para as medições de $T_{a}, T_{g}$, e UR. As medições de temperatura de superfície incluíram a face externa e interna da guarita, em MC, e, em $M E$, sobre o substrato, em seu interior e na face interna da guarita (cf. Figura 7). 
Figura 7 - Posicionamento dos sensores em MC e ME: Módulo controle (MC) e (b) Módulo experimental (ME)

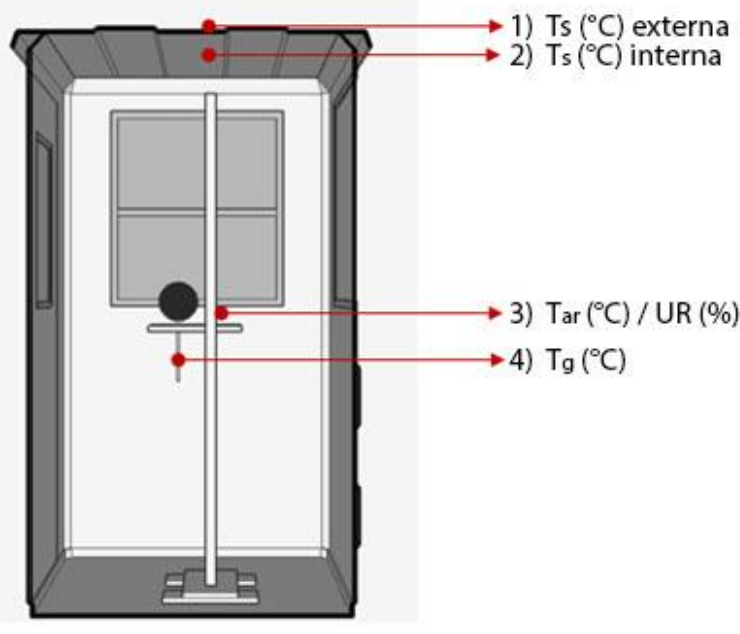

a)

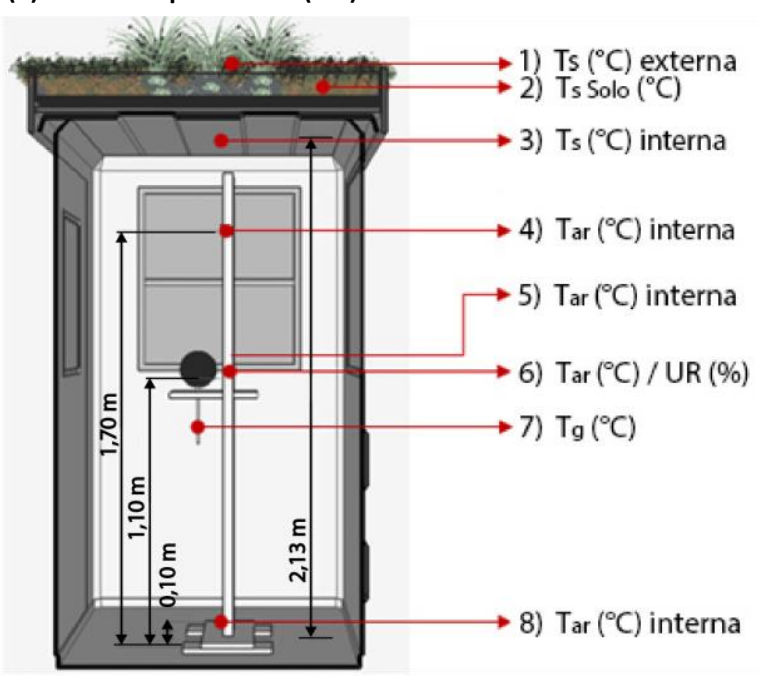

b)

Fonte: Os autores.

Quanto às temperaturas externas, utilizaram-se dois data loggers (HOBO U10-001 e LOGBOX-RHT, usado como backup), ambos inseridos no interior de abrigo meteorológico RS1 HOBO Onset.

As medições foram configuradas para coletas a cada 5 minutos, as quais foram posteriormente tratadas na base horária.

Levantamento termográfico

O uso da termografia possibilitou avaliar a aplicação da cobertura vegetada de forma mais global, para além das medições pontuais realizadas por meio de sensores de temperatura nas superfícies interna e externa da cobertura e no substrato. Com a termografia, transectos traçados linearmente possibilitam o estudo da variação da temperatura ao longo das superfícies.

Utilizou-se uma câmera termográfica modelo Fluke Tig, com foco manual. Ela possui sensibilidade térmica (NETD) $\leq 0,2{ }^{\circ} \mathrm{C}$ em $30^{\circ} \mathrm{C}$ (200 mK), faixa de temperatura de $-20^{\circ} \mathrm{C}$ a $+100{ }^{\circ} \mathrm{C}$ (sem calibração abaixo de $-10{ }^{\circ} \mathrm{C}$ ) e precisão de $\pm 5{ }^{\circ} \mathrm{C}$ ou $5 \%$. O software SmartView ${ }^{\circledR}$ foi usado para pós-tratamento e análise da imagem. Este permite a correção da emissividade e da temperatura sob as quais as imagens foram tomadas (assumiu-se a temperatura externa do horário da tomada).

As imagens foram tomadas em um dia de céu claro, em 24 de março de 2018, com irradiância solar alcançando $958 \mathrm{~W} / \mathrm{m}^{2}$ e a temperatura máxima beirando $29^{\circ} \mathrm{C}$ (a partir dos dados da estação automática de Curitiba-A807 (OMM: 86933) do Instituto Nacional de Meteorologia (INMET, 2018). A emissividade foi assumida como 0,95 em todas as situações.

Padrões normatizados de conforto do trabalho adotados para guaritas

Atualmente, inexistem normas de regularização das condições de trabalho no interior de guaritas. Sendo assim, consideraram-se como critérios de avaliação as recomendações gerais adotadas para ambientes de trabalho como as prescritas pela NR-24 (BRASIL, 1993) e pela NR-17 (BRASIL, 2015). Foram assumidas como referência as seguintes condições de conforto: (1) índice de temperatura efetiva (TE) entre $20^{\circ} \mathrm{C}$ e 23 ${ }^{\circ} \mathrm{C}$; (2) velocidade do ar inferior a $0,75 \mathrm{~m} / \mathrm{s}$; (3) umidade relativa do ar superior a $40 \%$. 
Outro parâmetro que possibilita a avaliação de estresse térmico é o cálculo do IBUTG. Este índice foi criado por Yaglou e Minard (1957) a partir de medição de campo de temperatura efetiva, derivado de duas quantidades: temperatura de bulbo úmido e temperatura de globo (D'AMBROSIO ALFANO, et al. 2014) e, considerando-se a média ponderada de temperatura do ar, verificam-se os limites de exposição ao calor (AULICIEMS; SZOKOLAY, 2007). Segundo a Norma Regulamentadora NR-15 (BRASIL, 2015), os limites de tolerância para exposição ao calor, a partir do índice de IBUTG, são definidos a partir do regime de trabalho intermitente (por hora). Para uma atividade considerada leve ("sentado, com movimentos moderados de braços, troncos e pernas, e de pé, com movimentos moderados de braços"; BRASIL, 2015, Anexo n. ${ }^{\circ} 3$ - Limites de Tolerância para Exposição ao (alor) em período de trabalho contínuo, a referência desse índice é de até $30^{\circ} \mathrm{C}$.

Parâmetros analisados

Além de médias e diferenças de temperatura interna do ar entre MC, ME e o ambiente externo, analisou-se a amplitude térmica (AT), a qual representa a diferença entre a temperatura máxima e mínima em determinado período de tempo. A partir da relação entre amplitude térmica interna e externa, adotou-se o coeficiente de Fator Decremental (f) para análise. Para comportamentos equivalentes nos ambientes interno e externo, o valor $f$ situa-se próximo à unidade. Valores abaixo de 1 denotam maior capacidade de estabilização térmica interna.

Para a avaliação térmica segundo a NR 17 (BRASIL, 2015), utilizando o índice de temperatura efetiva - TE, determinou-se a TE a partir da Equação 2:

$$
\mathrm{TE}=\mathrm{T}_{\mathrm{a}}-0,4 \times\left(\mathrm{T}_{\mathrm{a}}-10\right) \times\left(1-\frac{\mathrm{UR}}{100}\right)
$$

Na qual:

$$
\begin{aligned}
& \mathrm{T}_{\mathrm{a}}=\text { Temperatura de bulbo úmido }\left({ }^{\circ} \mathrm{C}\right) ; \\
& \mathrm{UR}=\text { Umidade relativa do } \operatorname{ar}(\%) .
\end{aligned}
$$

Pela Eq. 2, têm-se valores para análise dos ganhos de calor no ambiente interno, representados como em conforto, segundo a faixa de referência de $20^{\circ} \mathrm{C} \leq \mathrm{TE} \leq 23^{\circ} \mathrm{C}$. Valores identificados acima dessa faixa representam horas de calor, e abaixo desta, horas de frio.

Para avaliação das condições de estresse térmico segundo o índice IBUTG (pela NR 15, BRASIL, 2014), o qual equivale a um rápido diagnóstico do "efeito médio do calor" em um ambiente (LAMBERTS et al., 2016), consideraram-se as situações de janela fechada e aberta. Paras situações sem interferência da radiação solar (sem ganhos solares no ambiente), adota-se a Equação 3 e, quando há interferência da radiação solar, a Equação 4 .

$$
\begin{aligned}
& \text { IBUTG }=0,7 \times \mathrm{T}_{\mathrm{BN}}+0,3 \times \mathrm{T}_{\mathrm{g}} \\
& \text { IBUTG }=0,7 \times \mathrm{T}_{\mathrm{BN}}+0,2 \times \mathrm{T}_{\mathrm{BS}}+0,1 \times \mathrm{T}_{\mathrm{g}}
\end{aligned}
$$

Nas quais:

$\mathrm{T}_{\mathrm{BN}}=$ temperatura de bulbo úmido natural $\left({ }^{\circ} \mathrm{C}\right)$;

$\mathrm{T}_{\mathrm{g}}=$ temperatura de globo $\left({ }^{\circ} \mathrm{C}\right)$;

$\mathrm{T}_{\mathrm{BS}}=$ temperatura de bulbo seco $\left({ }^{\circ} \mathrm{C}\right)$.

Tomando-se como referência o valor de $30^{\circ} \mathrm{C}$ para o IBUTG, valores referentes ao índice acima desse patamar representam situações de estresse por calor de um indivíduo em um período de trabalho contínuo. 


\section{Resultados e discussões}

Os resultados são apresentados sob a forma de blocos, iniciando com as análises quanto à temperatura do ar, seguindo com as temperaturas superficiais e análise de conforto segundo TE (NR 17) e IBUTG (NR 15), análise termográfica e, por fim, análise do perfil vertical de temperatura do ar. Nas medições com a janela fechada foram monitoradas todas as variáveis (cf. Figura 7), contudo, nas configurações com janela aberta, as variáveis analisadas foram apenas as temperaturas superficiais em ambos os módulos. Isso porque, ao observar os dados coletados, o comportamento da temperatura do ar sofreu alterações em função da incidência de radiação direta no sensor, sendo estes, portanto, desconsiderados.

Temperatura do ar

São apresentados na Figura 8 os resultados referentes à temperatura do ar, conforme registrada no $M E$ e no $M C$ na sequência de monitoramentos. A análise restringe-se a três situações, quais sejam: SF, SVF e SVTF, 'substrato fechado', 'substrato com vegetação fechado' e ‘substrato com vegetação e tela fechado', uma vez que as configurações com janela aberta foram descartadas.

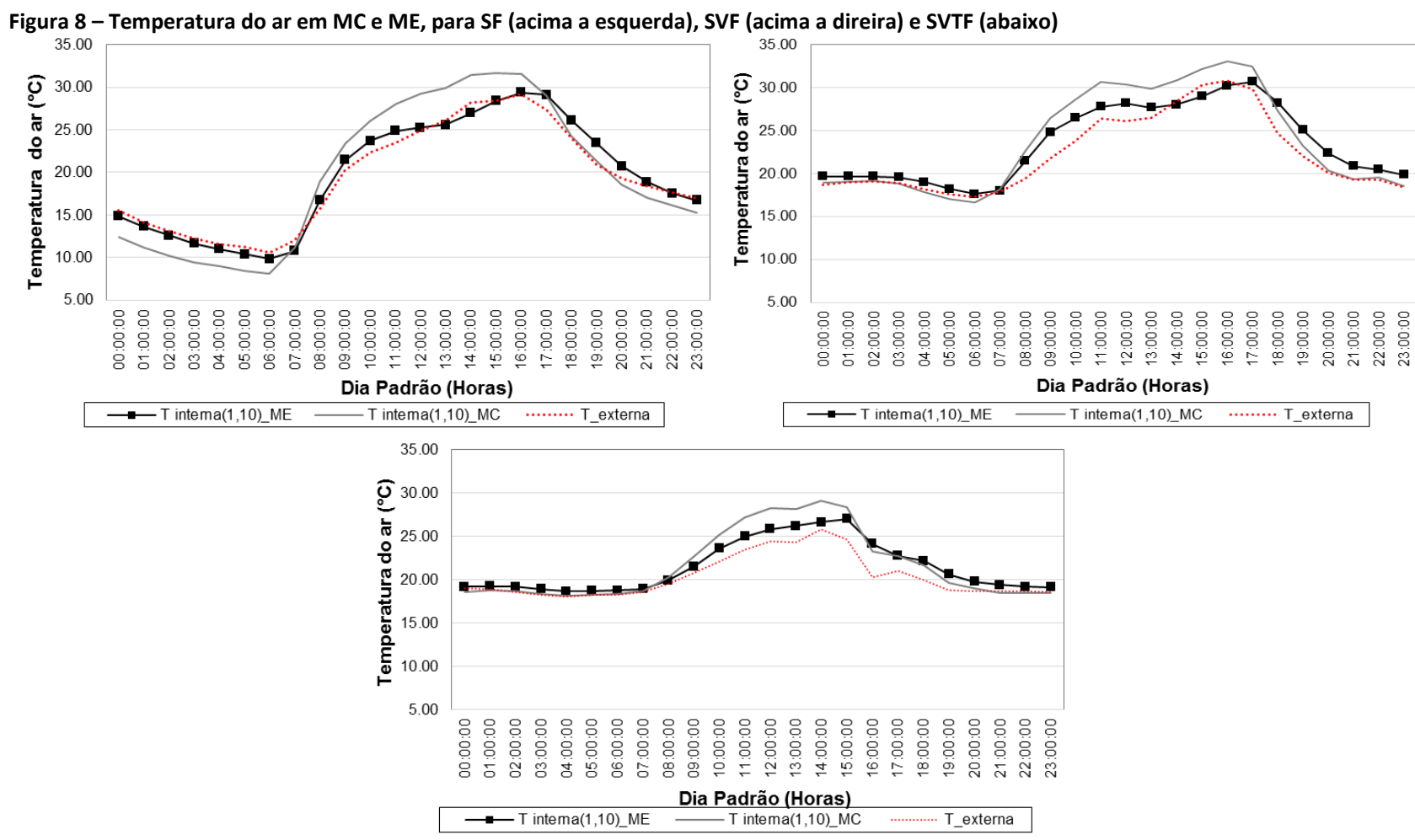

Fonte: Os autores.

Nota-se que as temperaturas internas são em geral mais altas no que no ambiente externo, com alguma vantagem de melhoria térmica em ME com a inclusão da massa térmica do substrato em relação a MC, situação SF (substrato com janela sombreada). As demais configurações apresentam comportamento semelhante frente às condições externas. A comparação direta entre comportamentos de ME é dificultada pela variabilidade dos padrões de temperatura, com maior flutuação térmica externa em SF e menor em SVTF (substrato com vegetação e tela com janela sombreada), devido às condições de tempo mais chuvosas com o avanço do verão curitibano. A Tabela 2 mostra as relações entre máximas em MC e ME auferidas nos dias padrão. 
Tabela 2 - Comparação entre temperatura ambiente interna máxima para as configurações SF, SVF e SVTF nos dias padrão

\begin{tabular}{cccc}
\hline Configuração & $\boldsymbol{T}_{\boldsymbol{a}} \mathrm{ME}\left({ }^{\circ} \mathrm{C}\right)$ & $\boldsymbol{T}_{\boldsymbol{a}} \mathrm{MC}\left({ }^{\circ} \mathrm{C}\right)$ & $\Delta \boldsymbol{T}_{\boldsymbol{a}}(\mathrm{K})$ \\
\hline SF & 28,7 & 31,2 & $-2,5$ \\
\hline SVF & 30,7 & 33,1 & $-2,4$ \\
\hline SVTF & 27,9 & 29,1 & $-2,1$ \\
\hline
\end{tabular}

Fonte: Os autores.

A redução notada em ME quanto às máximas diárias ocorre nos três casos, porém com pouca variabilidade e dentro da faixa de precisão especificada pelo fabricante para os sensores utilizados $\left( \pm 0,5^{\circ} \mathrm{C}\right)$. Efeitos térmicos adicionais com a inclusão da vegetação e do sombreamento não puderam ser comprovados em termos de reduções de temperatura do ar, possivelmente devido ao baixo índice de isolamento térmico da fibra de vidro (com uma resistência térmica $R_{t}$ de aproximadamente $0,06 \mathrm{~m}^{2} / \mathrm{K} . \mathrm{W}$ ) e da guarita como um todo.

Temperatura de superfície

Quanto às temperaturas superficiais sob a cobertura, comparativamente aos padrões sobre a guarita sem cobertura vegetada, diretamente sobre a fibra de vidro, nota-se em todos os casos um descolamento das curvas de temperatura em ME durante o dia, mais acentuadamente nos dias padrão. A Figura 9 mostra a comparação para a configuração SVTF (substrato com vegetação e tela com janela sombreada), situação com maior redução da temperatura superficial sob a cobertura comparativamente à face interna da cobertura de MC.

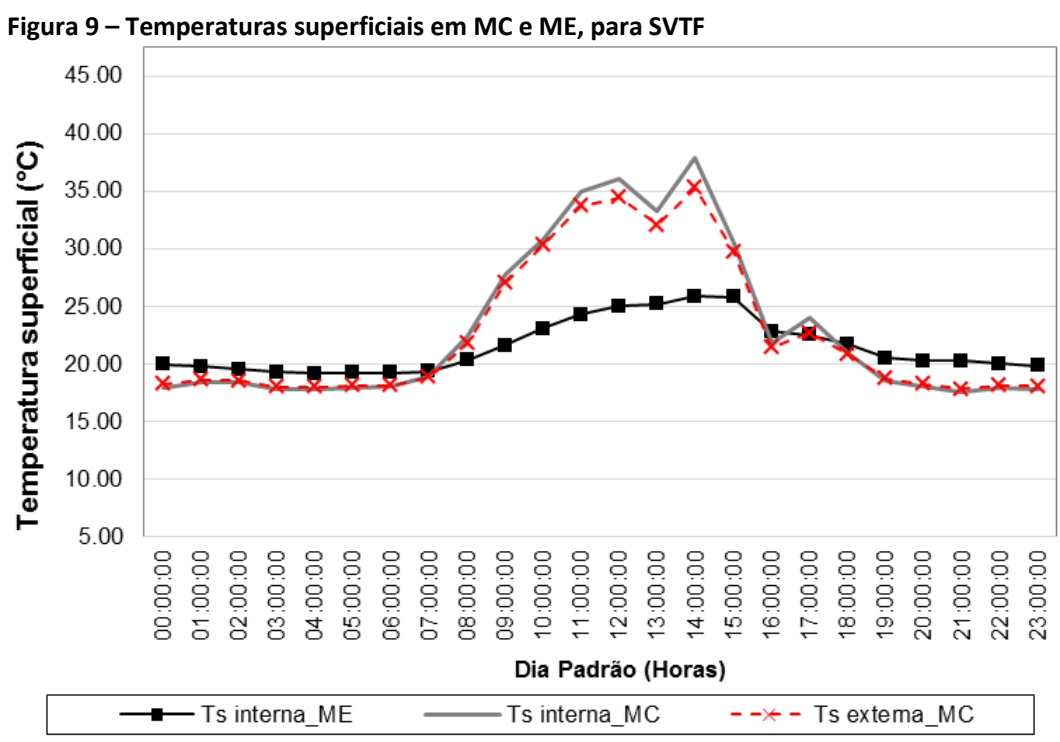

Fonte: Os autores.

A baixa resistência térmica da cobertura original $(M C)$ acarreta em temperaturas de superfície externa e interna muito próximas no módulo controle, enquanto que, em ME, a redução da temperatura máxima da superfície sob a cobertura vegetada é significativa, havendo algum amortecimento térmico no período noturno. A Tabela 3 mostra um resumo para as diversas configurações, comparando-se mais uma vez as relações entre máximas obtidas em $M C$ e $M E$ nos dias padrão, porém quanto às temperaturas superficiais sob a cobertura.

As reduções da temperatura foram mais impactantes na face interna da cobertura do que na temperatura interna do ar na guarita. Tais resultados replicam achados de um estudo realizado com as mesmas guaritas em uma etapa anterior da pesquisa, tratando 
de uso de barreiras radiantes (KRÜGER; SUETAKE; MATOSKI, 2018), com diferenças entre os módulos pouco perceptíveis em termos de temperatura do ar, porém mais significativas quanto às temperaturas superficiais sob a cobertura, o que está relacionado à baixa resistência da guarita como um todo. Tanto a vegetação quanto a tela de sombreamento contribuíram para a redução da temperatura superficial da cobertura, porém de forma mais discreta quando se compara à grande redução térmica sob a cobertura em ME vs. MC apenas com a introdução do substrato (cf. Tabela 3). A entrada de sol, porém, afeta o desempenho da cobertura, aquecendo o ambiente interno e possivelmente cedendo calor à superfície sob a cobertura. Mesmo assim, as situações com janela aberta (não sombreada) mostraram benefícios de ME em relação à $M C$.

Tabela 3 - Comparação entre temperatura superficial sob a cobertura (máxima diária) para as cinco configurações, nos dias padrão

\begin{tabular}{|c|c|c|c|c|}
\hline Situação & Configuração & $\boldsymbol{T}_{\boldsymbol{s}} \mathrm{ME}\left({ }^{\circ} \mathrm{C}\right)$ & $T_{s} \mathrm{MC}\left({ }^{\circ} \mathrm{C}\right)$ & $\Delta T_{s}(\mathrm{~K})$ \\
\hline \multirow{3}{*}{ Janela fechada } & SF & 29,9 & 39,8 & $-9,9$ \\
\hline & SVF & 31,1 & 41,2 & $-10,2$ \\
\hline & SVTF & 25,9 & 38,0 & $-12,1$ \\
\hline \multirow{2}{*}{ Janela aberta } & SVA & 35,6 & 43,4 & $-7,9$ \\
\hline & SVTA & 35,4 & 47,3 & $-11,9$ \\
\hline
\end{tabular}

TE e IBUTG

A Tabela 4 mostra a avaliação da temperatura efetiva para os dois módulos, com referência às categorias de horas de frio, conforto e calor, assim como o fator decremental (levando-se em conta para o cálculo $\mathrm{T}_{\mathrm{a}}$ ). Novamente, por ter sido notada uma influência da radiação solar direta no caso da janela aberta (não sombreada), a análise se restringe às situações SF, SVF e SVTF (substrato com janela sombreada, substrato com vegetação e com janela sombreada e substrato com vegetação e com janela sombreada), com as aberturas vedadas com foil.

Tabela 6 - Temperatura efetiva para ME e MC, referência do dia padrão para as diferentes configurações com janela fechada

\begin{tabular}{|c|c|c|c|c|c|c|c|}
\hline \multirow{2}{*}{\multicolumn{2}{|c|}{ Configurações }} & \multicolumn{2}{|c|}{ SF } & \multicolumn{2}{|c|}{ SVF } & \multicolumn{2}{|c|}{ SVTF } \\
\hline & & MC & $\mathrm{ME}$ & $\mathrm{MC}$ & $\mathrm{ME}$ & MC & $\mathrm{ME}$ \\
\hline Fator decremental (f & & 1,3 & 1,1 & 1,2 & 1,0 & 1,4 & 1,1 \\
\hline TE Máxima $\left({ }^{\circ} \mathrm{C}\right)$ & & 24,9 & 22,8 & 27,8 & 26,3 & 26,2 & 24,7 \\
\hline TE Mínima $\left({ }^{\circ} \mathrm{C}\right)$ & & 11,0 & 12,0 & 16,4 & 17,3 & 18,0 & 18,2 \\
\hline TE Média $\left({ }^{\circ} \mathrm{C}\right)$ & & 17,5 & 17,3 & 21,9 & 21,8 & 20,7 & 20,5 \\
\hline $\mathrm{TE}<20^{\circ} \mathrm{C}$ Frio & \multirow{3}{*}{$\begin{array}{c}\text { (horas/ } \\
24 \mathrm{~h} \text { ) }\end{array}$} & $14 \mathrm{~h}$ & $16 \mathrm{~h}$ & $12 \mathrm{~h}$ & $10 \mathrm{~h}$ & $13 \mathrm{~h}$ & $14 \mathrm{~h}$ \\
\hline $\begin{array}{c}20^{\circ} \mathrm{C} \leq \mathrm{TE} \leq 23^{\circ} \mathrm{C}- \\
\text { Conforto }\end{array}$ & & $3 h$ & $8 \mathrm{~h}$ & $2 \mathrm{~h}$ & $3 h$ & $5 \mathrm{~h}$ & $5 h$ \\
\hline TE $>23{ }^{\circ} \mathrm{C}$ Calor & & $7 \mathrm{~h}$ & Oh & $10 \mathrm{~h}$ & $11 \mathrm{~h}$ & $6 \mathrm{~h}$ & $5 \mathrm{~h}$ \\
\hline
\end{tabular}

Fonte: Os autores.

Constata-se um aumento de horas potencialmente em conforto para o ME, sobretudo nas configurações SF e SVF. A configuração SVTF apresentou ligeira atenuação da temperatura, com 1 hora a menos em condição de calor. A partir do coeficiente de fator decremental (valor $f$ ), conclui-se que a configuração SVF apresentou melhor desempenho quanto à estabilização térmica interna e, em seguida, as configurações SF e SVTF. A estabilização, contudo, devido às características da envoltória, atinge no máximo apenas as condições de amplitude térmica externa (para SVF, $\mathrm{f}=1$ ).

A Tabela 5 apresenta valores do índice de IBUTG, tendo como referência o valor igual ou acima de $30,0^{\circ} \mathrm{C}$ para identificar horas em estresse térmico por calor. 
KRÜGER, Eduardo et al.

Desempenho térmico de cobertura vegetada sobre guarita de fibra de vidro

\begin{tabular}{|c|c|c|c|c|c|}
\hline \multicolumn{2}{|c|}{ Configurações } & \multirow{2}{*}{$\frac{\text { IBUTG Máximo }\left({ }^{\circ} \mathrm{C}\right)}{21,3}$} & \multirow{2}{*}{$\frac{\text { IBUTG Mínimo }\left({ }^{\circ} \mathrm{C}\right)}{10,3}$} & \multirow{2}{*}{$\frac{\text { IBUTG Médio }\left({ }^{\circ} \mathrm{C}\right)}{15,4}$} & \multirow{2}{*}{$\frac{\text { IBUTG } \geq 30^{\circ} \mathrm{C}(\text { horas } / 24 \mathrm{~h})}{\text { Oh }}$} \\
\hline SF & $\mathrm{MC}$ & & & & \\
\hline & $\mathrm{ME}$ & 19,0 & 10,9 & 14,8 & $\mathrm{Oh}$ \\
\hline \multirow[t]{2}{*}{ SVF } & $\mathrm{MC}$ & 25,9 & 16,0 & 20,9 & $\mathrm{Oh}$ \\
\hline & $\mathrm{ME}$ & 24,6 & 16,8 & 20,8 & $\mathrm{Oh}$ \\
\hline \multirow[t]{2}{*}{ SVTF } & $\mathrm{MC}$ & 24,8 & 17,7 & 20,1 & $\mathrm{Oh}$ \\
\hline & $\mathrm{ME}$ & 23,6 & 17,6 & 19,7 & $\mathrm{Oh}$ \\
\hline
\end{tabular}

Fonte: Os autores.

Nota-se uma redução no valor do IBUTG entre MC e ME para as máximas e médias do dia padrão, com leve aumento nas mínimas internas (maior estabilização térmica interna em ME). Considerando as condições climáticas de Curitiba, mesmo em situação de verão, não houve situação de estresse por calor pelo índice IBUTC.

Análise termográfica

As avaliações com o uso da termografia confirmam os resultados observados em relação à presença da cobertura vegetada, mostrando complementarmente variações da temperatura superficial em função da maturidade do crescimento vegetal, da exposição do solo nu, dentre outras. As imagens das Figuras 10 e 11 apresentam as imagens termográficas em contraste com as fotografias tomadas com a câmara convencional, externa e internamente às duas guaritas.

Figura 10 - Imagens da cobertura tomadas externamente, para (a esquerda) ME e (a direita) MC - escalas de cores em ${ }^{\circ} \mathrm{C}$
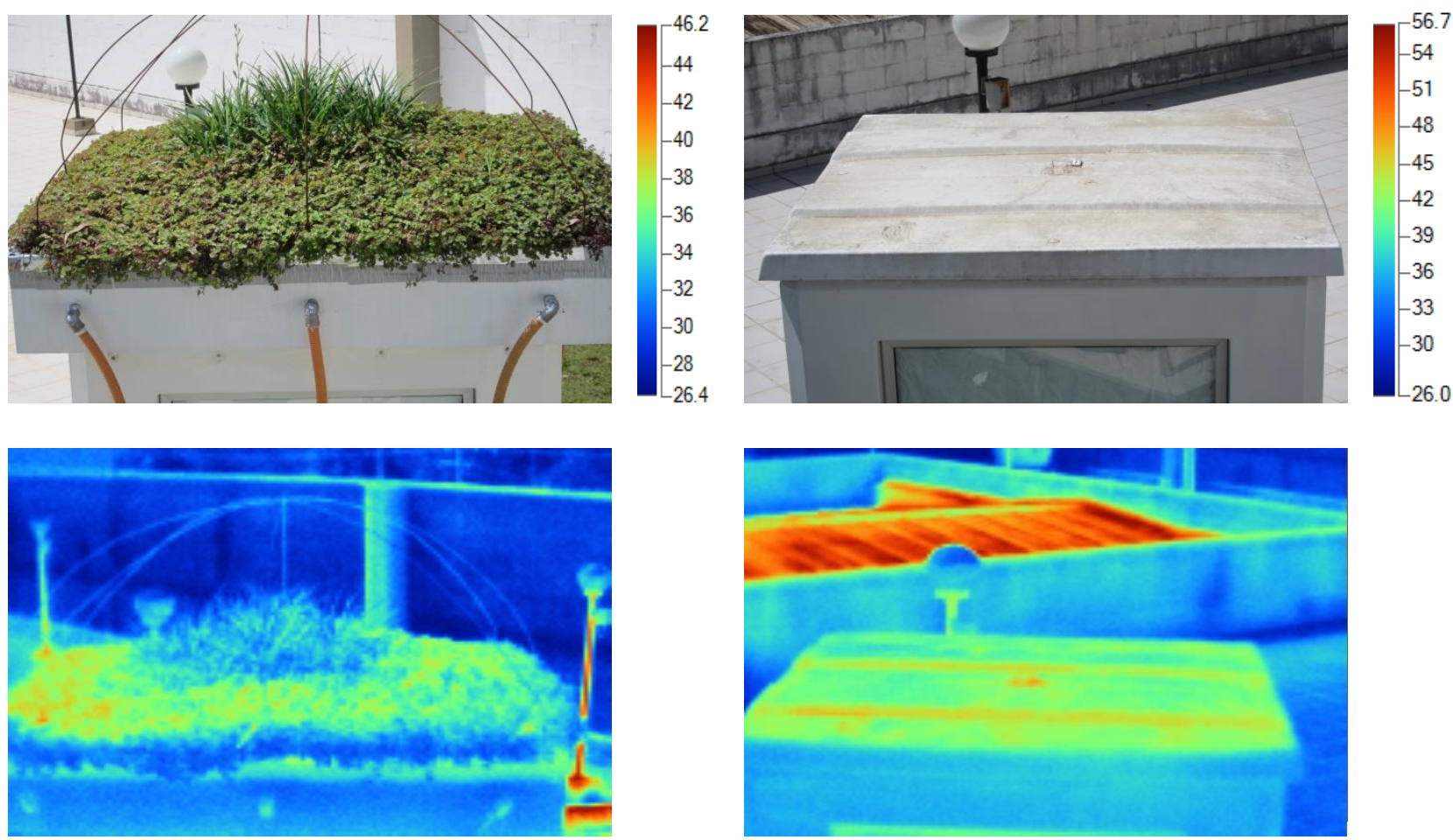

Fonte: Os autores.

Nas imagens das coberturas apresentadas na Figura 10 e nos valores apresentados na escala de cores falsas (dadas em ${ }^{\circ} \mathrm{C}$ ), é possível observar que $\mathrm{ME}$ permanece numa faixa de temperatura de superfície que varia de 28 a $38{ }^{\circ} \mathrm{C}$, em função da espécie arbórea, tamanho e nível de exposição do solo. No MC, a temperatura de superfície está numa faixa de $37{ }^{\circ} \mathrm{C}$ a $48{ }^{\circ} \mathrm{C}$, sendo notada certa homogeneidade da sua distribuição com alguns pontos nos quais ela se apresentou mais elevada. 


\section{KRÜGER, Eduardo et al.}

Desempenho térmico de cobertura vegetada sobre guarita de fibra de vidro

Figura 11 - Imagens da cobertura tomadas internamente, para (a esquerda) ME e (a direita) MC - escalas de cores em ${ }^{\circ} \mathrm{C}$
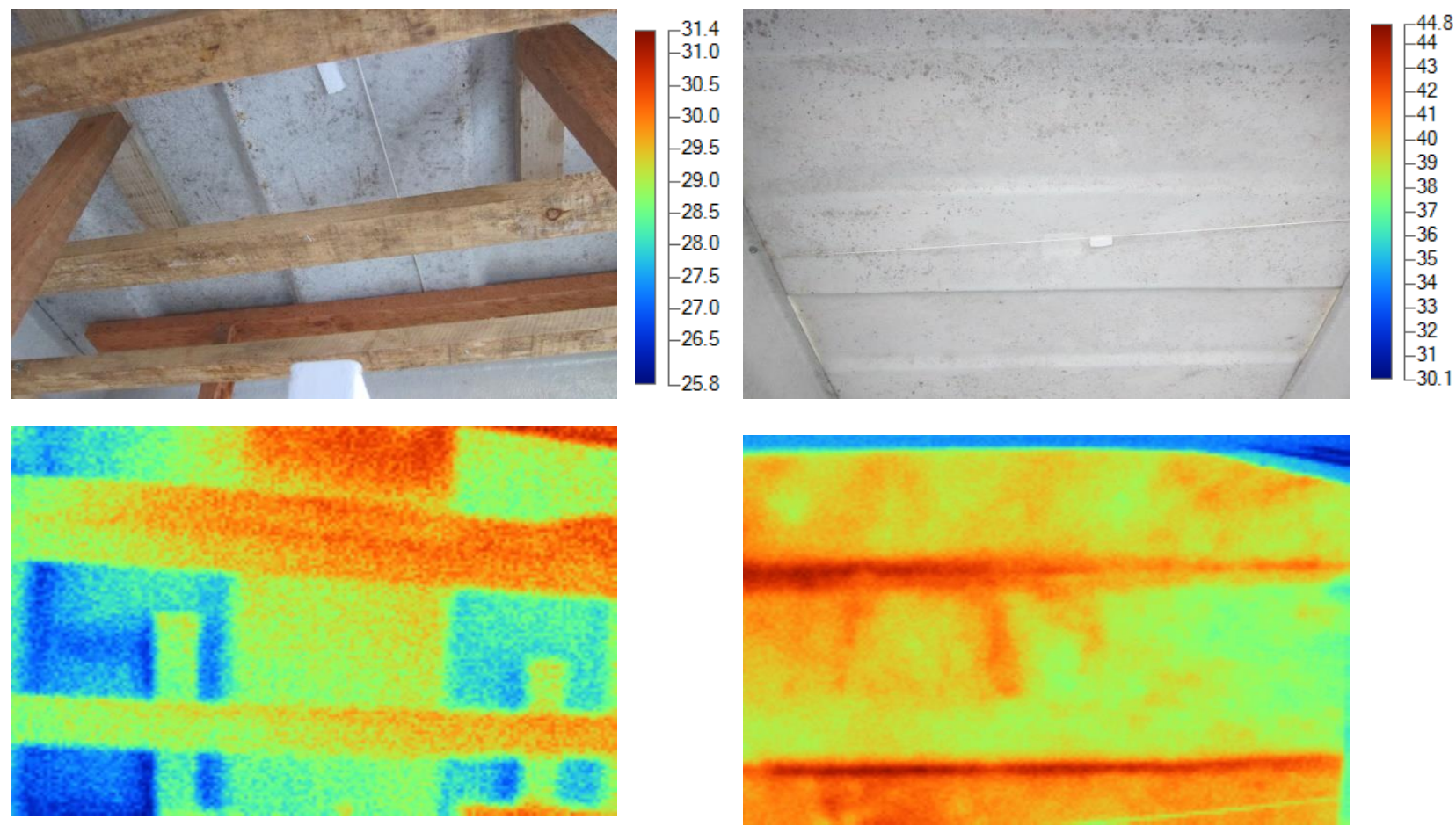

Fonte: Os autores.

Ao observar as tomadas internas, as diferenças entre os resultados para os dois módulos ficam ainda mais evidentes. Para ME, a faixa de temperatura não atinge os 30 ${ }^{\circ} \mathrm{C}$, enquanto que no $\mathrm{MC}$ seus valores mais baixos estão acima de $38^{\circ} \mathrm{C}$. Estes valores são aqueles observados no teto interno das guaritas.

Na Tabela 6 é apresentada uma síntese das temperaturas médias obtidas em cada situação. A mínima e a máxima referem-se aos valores extremos observados. Traçaramse retas (transectos) formando uma grade na região de interesse da imagem para restringir a leitura dos valores de temperatura de superfície aos pontos selecionados.

Tabela 6 - Dados dos transectos nas guaritas MC e ME (análise termográfica)

\begin{tabular}{cc}
\hline Condição & $\boldsymbol{T}_{\boldsymbol{s}}$ Média $\left({ }^{\circ} \mathrm{C}\right)$ \\
\hline Face externa ME & 33,8 \\
\hline Face externa MC & 38,0 \\
\hline Fiferença encontrada (média) - Face externa & 4,2 \\
\hline Face interna ME & 27,2 \\
\hline Diferença encontrada (média) - Face interna & 38,7 \\
\hline
\end{tabular}

Fonte: Os autores.

Na definição das trajetórias dos transectos, procurou-se identificar regiões de maior representatividade na imagem, traçando-se mais de uma reta quando havia muita variação nos valores, de modo a extrair médias e valores extremos (Figura 12). A partir dos valores lidos nestes pontos foram calculadas as médias para cada uma das superfícies estudadas. 


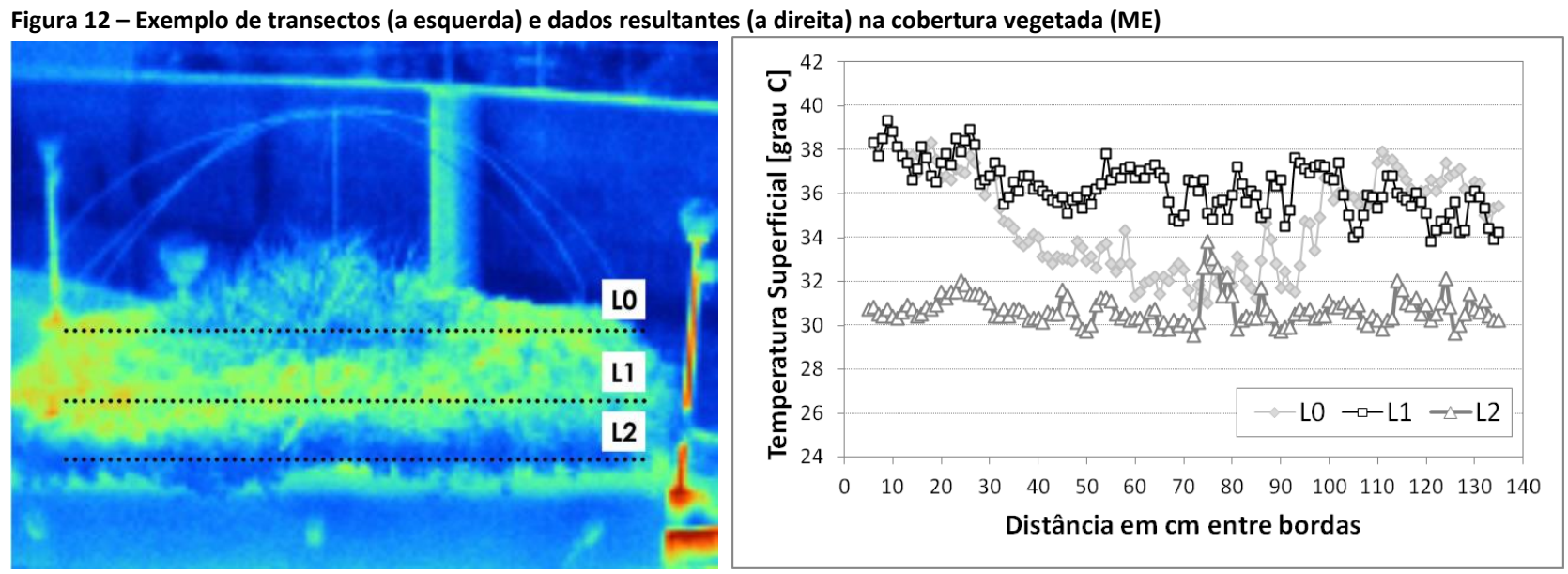

Fonte: Os autores.

Em MC, a temperatura da face interna aproximou-se da temperatura da cobertura, com um pequeno acréscimo devido à condição da guarita, que se encontrava fechada, sem ganhos solares, porém sem ventilação, portanto sem perdas por convecção natural internamente.

Em ME, os ganhos térmicos na face externa foram menores, porém com maior variabilidade térmica nos transectos (Figura 12) do que em MC. Observaram-se, nesse caso, temperaturas mais baixas no centro, onde a vegetação atingiu maior altura e principalmente nas bordas, devido ao efeito de sombreamento. Em MC, a concentração de valores mais altos ocorreu nas ranhuras, possivelmente devido à redução de perdas de calor por convecção.

Internamente, ME manteve a temperatura superficial significativamente inferior do que em $M C$, diferindo em $11,5 \mathrm{~K}$, o que se assemelha à diferença encontrada para as máximas no dia padrão para SVF conforme a análise de temperaturas de superfície (Tabela 3).

\section{Considerações finais}

O presente trabalho mostrou vantagens do sistema de cobertura vegetada em termos de redução da temperatura da face interna da cobertura, porém com pouco impacto na temperatura interna da guarita em fibra de vidro. As variações na temperatura de superfície, mais evidentes que na temperatura ambiente, se deram possivelmente em razão da baixa resistência térmica e da menor massa térmica da envoltória.

Ao se avaliar as diferentes composições de sistema de cobertura vegetada, infere-se que, para a configuração SF (substrato com janela sombreada), o substrato funciona tanto como isolante térmico quanto como elemento de maior capacidade térmica, este último impedindo sobreaquecimento, porém armazenando calor no período noturno. Os demais efeitos proporcionados pela vegetação e pela tela de sombreamento foram comparativamente menores, o que mostra a grande importância do substrato no controle térmico da edificação.

O estudo mostra a precariedade da construção de guaritas em fibra de vidro, sob o aspecto de desempenho térmico nas condições climáticas analisadas. Tal como em estudo anterior utilizando barreiras radiantes (KRÜGER; SUETAKE; MATOSKI, 2018), verificou-se que a melhoria térmica do ambiente interno exigiria uma otimização de todo o conjunto, não apenas da cobertura. Isso pode em parte ser explicado pela baixa relação entre área de cobertura e área de paredes da envoltória. Valores típicos para habitações padrão popular pode variar entre 50-80\% (DUMKE, 2002) enquanto que a guarita avaliada atinge um valor de $15 \%$ aproximadamente. Segundo a NBR 15220-3 
(ABNT, 2005), a resistência de paredes de blocos cerâmicos, comumente adotadas em habitações populares, situa-se entre $0.23-0.33 \mathrm{~m}^{2} / \mathrm{K} . \mathrm{W}$, ou seja, quatro a seis vezes maior que a da parede em fibra de vidro. Assim, estima-se que as vantagens térmicas de uma cobertura vegetada sobre uma edificação com características térmicas e com uma proporção entre volume interno e área de cobertura mais usual (50\% vs. 15\% para tal proporção) sejam mais significativas do que nas guaritas analisadas.

\section{Agradecimentos}

O presente trabalho foi realizado com apoio da Coordenação de Aperfeiçoamento de Pessoal de Nível Superior Brasil (CAPES), Programa de Demanda Social (DS), sob a forma de bolsa de Mestrado e com o apoio do Conselho Nacional de Desenvolvimento Científico e Tecnológico (CNPq), na forma de bolsa de Pós-Doutorado Sênior (PDS).

\section{Notas}

(1) Numeradas em algarismos arábicos, em notas de fim. No corpo do texto, utilizar chamada com numeração em sobrescrito. No corpo do texto, utilizar chamada com numeração em sobrescrito.

(2) Utilizar o estio PARC_Notes.

\section{Referências}

ABNT - ASSOCIAÇÃO BRASILEIRA DE NORMAS TÉCNICAS. NBR 15220-3: Desempenho térmico de edificações, parte 3: zoneamento bioclimático brasileiro e diretrizes construtivas para habitações unifamiliares de interesse social. Rio de Janeiro: ABNT, 2005.

AULICIEMS, A.; SZOKOLAY, S. PLEA Notes 3: Thermal Comfort, 2. ed. [s.l.]: PLEA \& UNIVERSITY OF QUEENSLAND DEPT. OF ARCHITECTURE, 2007. p. 66. Disponível em: http://www.plea-arch.org/index.php/plea-notes/. Acesso em: 26 jul. 2019.

BRASIL. Ministério do Trabalho e Emprego. NR 15 - Atividades e Operações Insalubres. Brasília: Ministério do Trabalho e Emprego, Brasília: Ministério do Trabalho e Emprego, 2014. Disponível em:

http://trabalho.gov.br/seguranca-e-saude-no-trabalho/normatizacao/normas-regulamentadoras/norma-

regulamentadora-n-15-atividades-e-operacoes-insalubres. Acesso em: 03 jul. 2017.

BRASIL. Ministério do Trabalho e Emprego. NR 17 - Ergonomia. Brasília: Ministério do Trabalho e Emprego, 2015. Disponível em http://trabalho.gov.br/seguranca-e-saude-no-trabalho/normatizacao/normas-

regulamentadoras/norma-regulamentadora-n-17-ergonomia. Acesso em: 03 jul. 2017.

BRASIL. Ministério do Trabalho e Emprego. NR 24 - Condições sanitárias e de conforto nos locais de trabalho. Brasília: Ministério do Trabalho e Emprego, 1993. Disponível em:

http://trabalho.gov.br/images/Documentos/SST/NR/NR24.pdf . Acesso em: 02 jul. 2017.

CORBELLA, O.; YANNAS, S. Em busca de uma arquitetura sustentável para os trópicos: conforto ambiental. Rio de Janeiro: Editorial Revan, 2003.

D'AMBROSIO ALFANO, F. R.; MALCHAIRE, J.; PALELLA, B. I.; RICCIO, G. WBGT index revisited after 60 years of use. Annals of occupational Hygiene, v. 58, n. 8, p. 955-970, 2014. DOI:doi.org/10.1093/annhyg/meu050

DUMKE, E. M. S. Avaliação do Desempenho Térmico de Sistemas Construtivos da Vila Tecnológica de Curitiba como Subsídio para o Estudo de Tecnologias Apropriadas em Habitação de Interesse Social. 2002. Dissertação (Mestrado em Tecnologia) - Programa de Pós-Graduação em Tecnologia, Universidade Federal Tecnológica do Paraná, Curitiba, 2002.

FBL - Fibras do Brasil. Disponível em: http://fblfibrasbrasil.com.br/. Acesso em: 26 jun. 2017. 
FERNANDES, L. C.; KRÜGER, E.; ROSSI, F. Análise de desempenho térmico de células teste dotadas de teto reservatório em clima subtropical. In: ENCONTRO NACIONAL DE CONFORTO NO AMBIENTE CONSTRUÍDO, 14.; ENCONTRO LATINO-AMERICANO DE CONFORTO NO AMBIENTE CONSTRUÍDO, 10., 2017, Balneário Camboriú. Anais [...] Porto Alegre: ANTAC, 2017. p. 926-935.

FERRAZ, I. L. O desempenho térmico de um sistema de cobertura verde em comparação ao sistema tradicional de cobertura com telha cerâmica. 2012. Dissertação (Mestrado) - Escola Politécnica da Universidade de São Paulo, São Paulo, 2012.

GUERRA JÚNIOR, José. C. Coberturas vivas, algumas observações técnicas para a sua implantação. 2013. Dissertação (Mestrado) - Pós-Graduação da Faculdade de Arquitetura e Urbanismo, Universidade de São Paulo, São Paulo, 2013.

IGRA - International Green Roof Association. Disponível em: http://www.igraworld.com/types_of_green_roofs/index.php. Acesso em: 02 ago. 2017.

INMET - INSTITUTO NACIONAL DE METEOROLOGIA. Disponível em: <http://www.inmet.gov.br/portal/>. Acesso em: 03 abr. 2018.

\section{IPARDES - INSTITUTO PARANAENSE DE DESENVOLVIMENTO ECONÔMICO E SOCIAL. Caderno Estatístico - Município de Curitiba, Abril 2018. Disponível em: \\ http://www.ipardes.gov.br/cadernos/MontaCadPdf1.php?Municipio=8000o\&btOk=ok. Acesso em: 14 mar. 2018. \\ KRÜGER, E.; SUETAKE, G.; MATOSKI, A. Evaluation of the thermal performance of insulation sheets in fiberglass security booths. Building and Environment, v. 136, p. 1-10, 2018. DOI:doi.org/10.1016/j.buildenv.2018.03.034}

KRÜGER, E.; BARBOSA, M. A. A influência da vegetação no microclima de áreas residenciais e na tecnologia construtiva: Estudo de caso realizado na Vila Tecnológica de Curitiba. In: ENCONTRO NACIONAL DE TECNOLOGIA DO AMBIENTE CONSTRUÍDO. 12., 2008, Porto Alegre. Anais [...] Porto Alegre: ANTAC, 2008. p. 1-10.

LAMBERTS, R.; XAVIER, A.A.; GOULART, S.; VECCHI, R. Desempenho térmico de edificações. Florianópolis: Laboratório de Eficiência Energética em Edificações, 2016. 239 p. Disponível em: http://www.labeee.ufsc.br/sites/default/files/disciplinas/ApostilaECV5161_v2016.pdf. Acesso em: 24 out. 2016.

LOPES, D. A. R. Análise do comportamento térmico de uma cobertura verde leve $(C V L)$ e diferentes sistemas de cobertura. 2007. Dissertação (Mestrado) - Programa de Pós-graduação em Ciências da Engenharia Ambiental, Escola de Engenharia de São Carlos, Universidade de São Paulo, São Carlos, 2007.

MILLER, A. P. R. R. Análise do comportamento de substrato para retenção de água pluvial para coberturas verdes extensivas em Curitiba-PR. 2014. Dissertação (Mestrado) - Engenharia da Construção Civil, Universidade Federal do Paraná, Curitiba, 2014.

MINKE, G. Techos verdes - Planificación, ejecución, consejos prácticos. Uruguay: Editora Fin de Siglo, 2004.

NIACHOU, A., PAPAKONSTANTINOU, K., SANTAMOURIS, M., TSANGRASSOULIS, A., \& MIHALAKAKOU, G. Analysis of the green roof thermal properties and investigation of its energy performance. Energy and buildings, v. 33, n. 7 , p. 719-729, 2001. DOI:doi.org/10.1016/S0378-7788(01)00062-7

NOYA, M.G.; CUQUEL, F.L.; SCHAFER, G.; ARMINDO, R.A. Substrates for cultivating herbaceous perennial plants in extensive green roofs. Ecological Engineering, v. 102, p. 662-669, 2017. DOI:doi.org/10.1016/j.ecoleng.2017.02.042

PEEL, M. C.; FINLAYSON, B. L.; MCMAHON, T. A. Updated world map of the Köppen-Geiger climate classification, Hydrology and Earth System Sciences, v. 11, p. 1633-1644, 2007. DOI:doi.org/10.1127/0941-2948/2006/0130

RAJI, B.; TENPIERIK, M. J.; VAN DEN DOBBELSTEEN, A. The impact of greening systems on building energy performance: A literature review. Renewable and Sustainable Energy Reviews, v. 45, p. 610-623, 2015.

DOI:doi.org/10.1016/j.rser.2015.02.011 
RAZZAGHMANESH, M.; BEECHAM, S.; KAZEMI, F. The growth and survival of plants in urban green roofs in a dry climate. Science of the Total Environment, v. 476, p. 288-297, 2014. DOI:doi.org/10.1016/j.scitotenv.2014.01.014

SAVI, A. C. Telhados Verdes: uma análise da influência das espécies vegetais no seu desempenho na cidade de Curitiba. 2015. Monografia (Especialização) - Programa de Pós-Graduação em Engenharia de Construção Civil, Universidade Federal do Paraná, Curitiba, 2015.

SAVI, C. A. Telhados verdes: análise comparativa de custo com sistemas tradicionais de cobertura. 2012. Monografia (Especialização em Construções Sustentáveis) - Universidade Tecnológica Federal do Paraná, Curitiba, 2012. Disponível em: http://repositorio.roca.utfpr.edu.br/jspui/bitstream/1/788/1/CT_CECONS_II2012_01.pdf. Acesso em: 19 mar. 2018.

TABARES-VELASCO, P. C.; SREBRIC, J. A heat transfer model for assessment of plant based roofing systems in summer conditions. Building and Environment, v. 49, p. 310-323, 2012. DOI:doi.org/10.1016/j.buildenv.2011.07.019

TECH COMPOSITES - Aplicação de material de PRFV na construção civil. Disponível em:

http://techcomposites.com.br/aplicacao-de-material-de-prfv-na-construcao-civil/. Acesso em: 06 abr, 2018.

TRITON SYSTEMS. Green Roofs. 2011. Disponível em <http://www.tritonsystems.co.uk/prode1.php\#p1>. Acesso em: 9 jan. 2018.

VERA, S.; PINTO, C.; TABARES-VELASCO, P. C.; BUSTAMANTE, W.; VICTORERO, F.; GIRONÁS, J.; BONILLA, C. A. Influence of vegetation, substrate, and thermal insulation of an extensive vegetated roof on the thermal performance of retail stores in semiarid and marine climates. Energy and Buildings, v. 146, p. 312-321, 2017. DOI:doi.org/10.1016/j.enbuild.2017.04.037

VIJAYARAGHAVAN, K. Green roofs: A critical review on the role of components, benefits, limitations and trends. Renewable and Sustainable Energy Reviews, v. 57, p. 740-752, 2016. DOI:doi.org/10.1016/j.rser.2015.12.119

YAGLOU, C.; MINARD, D. Control of heat casualties at military training centers. Archives of Industrial Health, v. 16, p. 302-305, 1957.

YEANG, Ken. Ecodesign: a manual for ecological design. Londres: Willey Academy, 2006.

\section{'Eduardo Krüger}

Engenheiro Civil. Doutor em Arquitetura (Hannover, Alemanha). Professor Associado IV da Universidade Tecnológica Federal do Paraná (UTFPR), professor do Departamento de Construção Civil e do Programa de PósGraduação em Engenharia Civil. UTFPR / Campus Curitiba / Sede Ecoville. Endereço postal: Rua Deputado Heitor Alencar Furtado, 4900 Curitiba - PR. CEP 81280-340.

\section{${ }^{2}$ Patricia Regina Chaves Drach}

Arquiteta e Urbanista. Doutora em Modelagem Computacional. Professora Adjunta do Departamento de Arquitetura e Urbanismo da Escola Superior de Desenho Industrial da Universidade do Estado do Rio de Janeiro DAU/ESDI/UERJ e Professora Permanente do Programa de Pós-graduação em Urbanismo da Universidade Federal do Rio de Janeiro - PROURB/UFRJ. Endereço postal: Rua Sesquicentenário 100/102 - Independência, Petrópolis RJ. CEP 25645-560.

\section{Cintia Akemi Tamura}

Arquiteta e Urbanista. Doutora em Tecnologia e Desenvolvimento. Pesquisadora Credenciada - PPGEC - UTFPR. Endereço postal: Rua Solimões, 1487 apto. 415-D, Curitiba - PR. CEP 80810-070.

\section{Francine Kaviski}

Arquiteta e Urbanista. Mestre em Engenharia Civil. Docente do curso de Arquitetura do Centro Universitário Autônomo do Brasil - UniBrasil. Endereço postal: Rua Konrad Adenauer, 442 - Tarumã, Curitiba - PR. CEP 82821-020. 